\title{
The Modified Method of Luxol Fast Blue for Paraffin-Embedded Myelin Sheath Staining
}

\author{
El Método Modificado de Luxol Fast Blue para la Tinción de Mielina Fijada en Parafina
}

\author{
Ensieh Sajadi $^{1,2}$; Amir Raoofi ${ }^{3}$; Shabnam Abdi ${ }^{4}$; Hadi Azimi ${ }^{5}$ \& Mohammad-Amin Abdollahifar ${ }^{1,2}$
}

SAJADI, E.; RAOOFI, A.; ABDI, S.; AZIMI, H. \& ABDOLLAHIFAR, M. A. The modified method of Luxol fast blue for paraffinembedded myelin sheath staining. Int. J. Morphol., 38(5):1197-1200, 2020.

SUMMARY: Histological techniques are the study of animal and human tissues through staining and examining them under a microscope. To demonstrate the axonal degeneration and demyelination in histological studies, the Luxol Fast Blue staining is gold standard techniques. In this study, a new histochemical method based on modified Luxol Fast Blue for the staining of the myelin sheath in sciatic nerve tissues described. The sciatic nerves of rats were removed and then the sciatic nerve was immersed in $10 \%$ formaldehyde for one week and embedded in paraffin block. Next, thin sections $(5 \mu \mathrm{m})$ were cut, using a microtome and stained with conventional and modified Luxol Fast Blue. Our results showed that a new method of modified Luxol Fast Blue staining can accurately identify the myelin in the sciatic nerve fibers. The current study showed that the Luxol Fast Blue combination with Light Green has a good effect on myelin coloration, and the results of this study are comparable to LFB combination with Sirius red.

KEY WORDS: Myelin sheath; Luxol Fast Blue; Light Microscope.

\section{INTRODUCTION}

Histological study is the microscopic techniques (including electron and light microscope) to examine animal and human tissues by staining and examining them under a microscope. In order to examine tissue characteristics and microscopic structures of the cells, a number of methods are implemented (Engbaek \& Johansen, 1979). Histological staining includes a series of technique processes performed to prepare sample tissues by staining using histological stains so as to aid in the microscope study (Carriel et al., 2011). During recent years there have been great changes introduced in techniques used for histological staining, in terms of chemical, molecular biology assays, and immunological techniques collectively, which have greatly resulted in facilitating the study of organs and tissues (Larsen et al., 2003).

Peripheral nerve fibers are histological structures composed of the neuronal axons, myelin sheaths synthesized by Schwann cells and a collagen-rich extracellular matrix (Mills, 2007). The Schwann cells can form lipid-rich multilayered myelin sheaths that can establish the myelinated fibers (Struzyna et al., 2015). The use of histochemical techniques provides information about pathophysiological conditions in peripheral nerves (Mills; Carriel et al., 2017).

Several techniques for study of peripheral nerve fibers are available. One of the most reliable methods and gold standard techniques used to demonstrate the axonal degeneration and demyelination in histological studies is Luxol Fast Blue (LFB) staining, toluidine blue staining and immunohistochemistry staining, which allows the accurate identification of most myelinated fibers (Mills). LFB was introduced by Kluever and Barrera in 1953. LFB dye has a copper phthalocyanine chromogen insoluble in water, but soluble in alcohol, which intensely stains myelin sheaths (Kluver \& Barrera, 1953; Carriel et al.). However, what chemical bases are behind this reaction is still unknown. Luxol Fast Blue staining is differentiated with lithium carbonate and then contrasted with cresyl violet. Conventional Sirius red method is the method especially useful for the analysis of nervous system. Introduced in 2011, this method combines the specificity and sensibility of LFB, Picrosirius red (Sirius red F3B and picric acid) staining and Harris' Hematoxylin (as

\footnotetext{
${ }^{1}$ Hearing Disorders Research Center, Loghman Hakim Medical Center, Shahid Beheshti University of Medical Sciences, Tehran, Iran.

${ }^{2}$ Department of Biology and Anatomical Sciences, School of Medicine, ShahidBeheshti University of Medical Sciences, Tehran, Iran.

${ }^{3}$ Leishmaniasis Research Center, Department of Anatomy, Sabzevar University of Medical Sciences, Sabzevar, Iran.

${ }^{4}$ Department of Anatomical Sciences \& Cognitive Neuroscience, Faculty of Medicine, Tehran Medical Sciences, Islamic Azad University, Tehran, Iran.

${ }^{5}$ Department of English Language Teaching, School of Medicine, Shahid Beheshti University of Medical Sciences, Tehran, Iran.
} 
nuclear contrast) (Carriel et al.). In this work, we describe a new histochemical method based on conventional luxol fast blue and Light Green methods was used instead of the Sirius red, for the simultaneous staining of the myelin sheath in sciatic nerve tissues.

\section{MATERIAL AND METHOD}

Animal. In this study, 12 adult male rats were used. Each rat has been stored in a lab with the standard conditions at 22-24 ${ }^{\circ} \mathrm{C}$ receiving necessary water and food freely. Moreover, the approval of the animals experiment has been received from the Ethics Committee of the Shahid Beheshti University of Medical Sciences (IR.SBMU.RETECH. REC.1396.544). The rats have been categorized into 2 groups; group (I), conventional LFB, group (II), modified LFB.

Tissue preparation. The rats were deeply anesthetized and decapitated. Then, their sciatic nerves were exposed via an incision along the midpoint of the thigh. The right sciatic nerve was immersed in $10 \%$ formaldehyde for one week and then embedded in paraffin block. Next, thin sections ( 5 $\mathrm{mm}$ ) were cut using a microtome and stained with LFB.

Conventional LFB staining procedure was carried out as follows: Perform the steps $\mathbf{1 - 5}$ as described above

1.De-wax paraffin sections in xylene and hydrate in 100 and $95 \%$ ethanol.

2. Stain sections in $0.1 \%$ LFB diluted in $95 \%$ ethanol with $2.5 \mathrm{ml}$ of $10 \%$ acetic acid at $56^{\circ} \mathrm{C} 16-24 \mathrm{~h}$ (overnight).
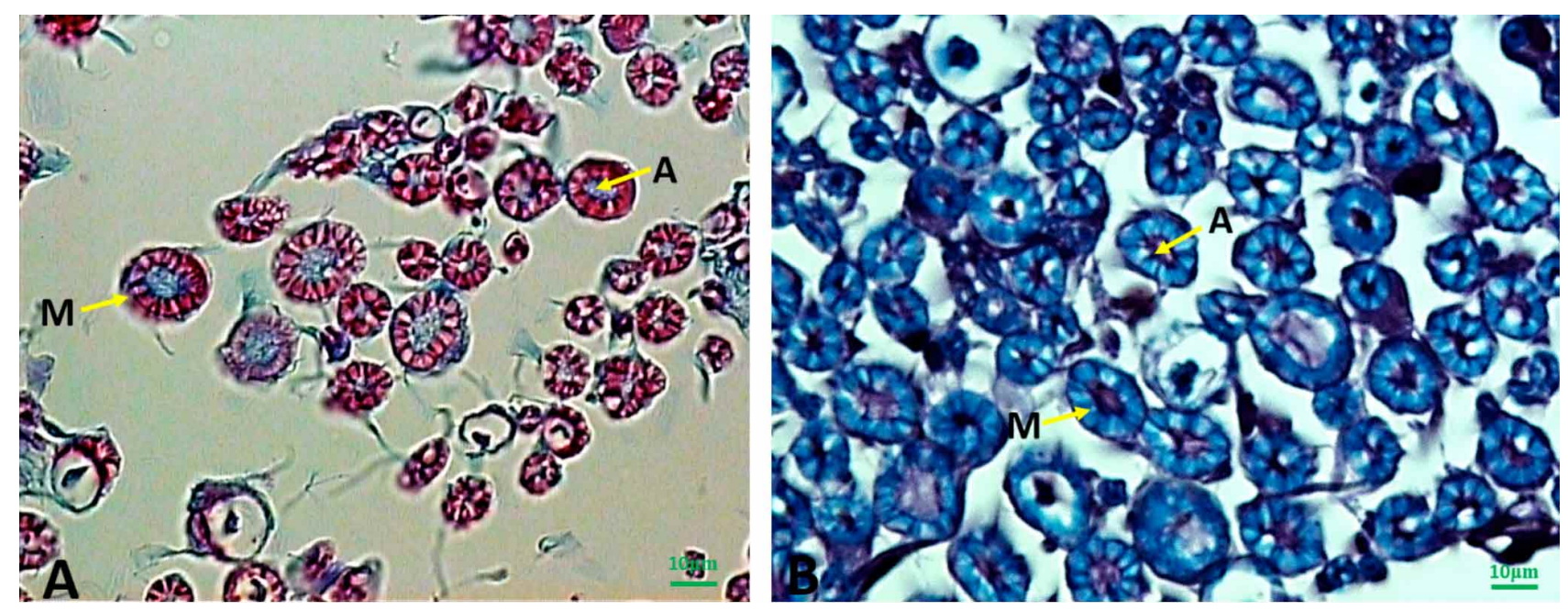

Fig. 1. (A) Conventional LFB staining in sciatic nerve of normal rat. Note that the myelin sheath (M) is red and axon (A) (yellow arrows). (B) Modified LFB staining in sciatic nerve of normal rat. Note that the myelin sheath (M) is blue and axon (A) (yellow arrows). In peripheral nerves, LFB method intensely stain myelinated nerve fibers in blue.
3. Rinse in $95 \%$ ethanol, and then in distilled water.

4. Differentiate in $0.05 \%$ lithium carbonate until gray and white matters can be distinguished.

5. Rinse in $70 \%$ ethanol, two changes.

6. Counterstain in $0.1 \%$ aqueous solution of crystal violet with $5 \mathrm{mg}$ oxalic acid for $10 \mathrm{~min}$ at $56^{\circ} \mathrm{C}$ for 2 minutes.

7. Rinse in distilled water for 5 minutes.

8. Stain sections in in $0.2 \%$ sirius red for 10 minutes.

9. Rinse in distilled water, two changes.

10. Counterstain in Harris hematoxylin for 3 minutes.

11. Rinse in tap water for 3-5 minutes.

12. Dehydrate in increasing concentrations of ethanol (70 $\%, 95 \% 99 \%$ ).

13. Clear using two changes of xylene and mount using a hydrophobic medium. Let slides dry at room temperature for at least 15 minutes.

The modified LFB procedure: Perform the steps 1-7 as described above

1. Stain sections in light green for 10 minutes.

2. Rinse in distilled water, two changes.

3. Counterstain in Harris hematoxylin for 3 minutes.

4. Rinse in tap water for 3-5 minutes.

5. Dehydrate in increasing concentrations of ethanol (70 $\%, 95 \% 99 \%$ ).

6. Clear using two changes of xylene and mount using a hydrophobic medium. Let slides dry at room temperature for at least 15 minutes.

The tissue sections staining with LFB were examined under a light microscope (Nikon E200, Tokyo, Japan), and images were captured with a Nikon Digital Camera (Nikon, Tokyo, Japan). 


\section{RESULTS}

The analysis with LFB method allowed us to identify the myelin sheath of the myelinated nerve fibers. Figure 1 (A and $B$ ) shows the results of transverse sections of sciatic nerve obtained from the conventional LFB and modified LFB staining. The specific identification of the myelin sheath (blue) and nerve fibers (red) were observed based on the reaction with LFB staining (Fig 1A). With the new modified LFB histological method, myelin was observed in blue, while the axon was clearly distinguishable from the myelin sheath with high contrast in sciatic nerve (Fig. 1B). With this new method it was possible to accurately identify the sciatic nerve based on morphological and histochemical parameters (Fig. 1B).

\section{DISCUSSION}

One of the gold standard method for staining sciatic nerve tissue to obtain imaging of myelinated fibers by LFB staining. The results of the current study showed that high resolution imaging of rat sciatic nerve myelinated fibers can also be obtained using LFB staining with only the addition of a light green $2 \%$. The advantages of staining with LFB with light green $2 \%$ instead LFB with Sirius red $0.2 \%$ are two main limitations: (1) Sirius red is much more expensive than light green, which can be found only in specialized laboratories; (2) LFB and Sirius red $0.2 \%$ preparation is very difficult.

The present study showed a new modified histological staining method based on conventional LFB for the staining of myelin sheath in peripheral nerve fibers. Histopathological analysis and tissue engineering from peripheral nerves should be accompanied by histological staining of nerve tissue (McNally \& Peters, 1998). Observations of peripheral nerve tissue using light microscopy have enabled us to evaluate the main morphological characteristics. However, the use of LFB staining methods, makes it necessary to evaluate the myelin sheath. In histology, the LFB method is often used in the histopathology to study myelin in CNS and PNS (McNally \& Peters; Carriel et al.).

Several techniques for identifying myelin have been made using light and electron microscopes (Stilwell, 1957; Schmued et al., 1982; McNally \& Peters; Tolivia et al., 1994; Schmued \& Slikker, 1999; Savaskan et al., 2009). In these methods, it is possible to evaluate the morphological parameters in the myelin sheath. However, due to the expensive of these methods, it is necessary to use the other methods that have inexpensive, quick and easy coloring methods (Kluver \& Barrera; Tolivia et al.; McNally \& Peters). The newly developed LFB method, based on conventional methods, allows us to evaluate the morphological characteristics of the sciatic nerve (McNally $\&$ Peters; Schmued \& Slikker). However, the advantages of the modified LFB Method using light green, the diagnosis of myelin sheath with the same pattern of staining and the precision of the conventional LFB method, is comparable to the conventional LFB method (Stilwell; Schmued et al.; Tolivia et al.).

As a result, the use of this new method of histology allows us to examine the structure of the sciatic nerve tissue. In the present study, we performed a LFB with Light Green. The results of the present study showed that the LFB combination with Light Green is a good effect on myelin coloration, and the results of this study are comparable to LFB combination with Sirius red. However, we assume that this new histological method can be useful in pathology and tissue engineering.

\section{ACKNOWLEDGEMENTS}

Animal studies of this work were performed at Hearing Disorders Research Center, Loghman Hakim Medical Center, Shahid Beheshti University of Medical Sciences, Tehran, Iran. Therefore, In vivo part of this study is derived from the thesis formulated by Ensieh Sajadi, the MSc student at Department of Biology and Anatomical Sciences, School of Medicine, Shahid Beheshti University of Medical Sciences, Tehran, Iran. (Registration No. 1397270). The work was financially supported by the Hearing Disorders Research Center, Loghman Hakim Medical.

SAJADI, E.; RAOOFI, A.; ABDI, S.; AZIMI, H. \& ABDOLLAHIFAR, M.A. Método modificado de Luxol Fast Blue para la tinción de mielina fijada en parafina. Int. J. Morphol., 38 (5):1197-1200, 2020.

RESUMEN: Las técnicas histológicas son el estudio de tejidos animales y humanos mediante tinción y examen bajo un microscopio. Para demostrar la degeneración axonal y la desmielinización en estudios histológicos, la tinción Luxol Fast Blue es una técnica estándar de oro. En este estudio, se describe un nuevo método histoquímico basado en Luxol Fast Blue modificado para la tinción de mielina en los tejidos del nervio ciático. Se seccionaron los nervios ciáticos de ratas y luego el nervio ciático se sumergió en formaldehído al $10 \%$ durante una semana y se fijó en bloque de parafina. Posteriormente, se cortaron secciones del- 
gadas $(5 \mu \mathrm{m})$ usando un microtomo y se tiñeron con Luxol Fast Blue convencional y modificado. Nuestros resultados mostraron que un nuevo método de tinción Luxol Fast Blue modificado puede identificar con precisión la mielina en las fibras del nervio ciático. El estudio actual mostró que la combinación Luxol Fast Blue con Light Green es un buen efecto sobre la coloración de mielina, y los resultados de este estudio son comparables a la combinación LFB con Sirius red.

PALABRAS CLAVE: Vaina de mielina; Luxol Fast Blue; Microscopio de luz.

\section{REFERENCES}

Carriel, V.; Campos, A.; Alaminos, M.; Raimondo, S. \& Geuna, S. Staining methods for normal and regenerative myelin in the nervous system. Methods Mol. Biol., 1560:207-18, 2017.

Carriel, V.; Garzón, I.; Alaminos, M. \& Campos, A. Evaluation of myelin sheath and collagen reorganization pattern in a model of peripheral nerve regeneration using an integrated histochemical approach. Histochem. Cell Biol., 136(6):709-17, 2011.

Engbaek, K. \& Johansen, K. S. A new technique for Gram staining paraffinembedded tissue. J. Clin. Pathol., 32(2):187-90, 1979.

Kluver, H. \& Barrera, E. A method for the combined staining of cells and fibers in the nervous system. J. Neuropathol. Exp. Neurol., 12(4):4003, 1953 .

Larsen, M.; Bjarkam, C. R.; Stoltenberg, M.; Sørensen, J. C. \& Danscher, G. An autometallographic technique for myelin staining in formaldehyde-fixed tissue. Histol. Histopathol., 18(4):1125-30, 2003.

McNally, K. J. \& Peters, A. A new method for intense staining of myelin. J. Histochem. Cytochem., 46(4):541-5, 1998.

Mills, S. E. Histology for Pathologists. $3^{\text {rd }}$ ed. Philadelphia, Lippincott Williams and Wilkins, 2007.

Savaskan, N. E.; Weinmann, O.; Heimrich, B. \& Eyupoglu, I. Y. High resolution neurochemical gold staining method for myelin in peripheral and central nervous system at the light- and electron-microscopic level. Cell Tissue Res., 337(2):213-21, 2009.

Schmued, L. \& Slikker, W. Jr. Black-gold: a simple, high-resolution histochemical label for normal and pathological myelin in brain tissue sections. Brain Res., 837(1-2):289-97, 1999.

Schmued, L. C.; Swanson, L. W. \& Sawchenko, P. E. Some fluorescent counterstains for neuroanatomical studies. J. Histochem. Cytochem., 30(2):123-8, 1982.

Stilwell, D. L. A sudan black B myelin stain for peripheral nerves. Stain Technol., 32(1):19-23, 1957.

Struzyna, L. A.; Harris, J. P.; Katiyar, K. S.; Chen, H. I. \& Cullen, D. K. Restoring nervous system structure and function using tissue engineered living scaffolds. Neural Regen. Res., 10(5):679-85, 2015.

Tolivia, J.; Navarro, A. \& Tolivia, D. Differential staining of nerve cells and fibres for sections of paraffin-embedded material in mammalian central nervous system. Histochemistry, 102(2):101-4, 1994.
Corresponding author:

Mohammad-Amin Abdollahifar

Department of Biology and Anatomical Sciences

School of Medicine

Shahid Beheshti University of Medical Sciences

Tehran

IRAN

E-mail: abdollahima@sbmu.ac.ir

Received: 04-04-2020

Accepted: 03-05-2020 